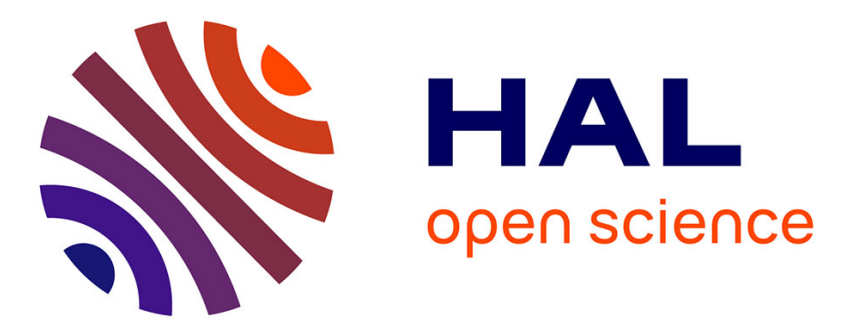

\title{
Autostereoscopic transparent display using a wedge light guide and a holographic optical element
}

Thomas Crespel, Patrick Reuter, Xavier Granier, Adrian Travis

\section{To cite this version:}

Thomas Crespel, Patrick Reuter, Xavier Granier, Adrian Travis. Autostereoscopic transparent display using a wedge light guide and a holographic optical element. Digital Holography and ThreeDimensional Imaging, May 2019, Bordeaux, France. pp.M3A.4, 10.1364/DH.2019.M3A.4 . hal02129569

\section{HAL Id: hal-02129569 \\ https://hal.inria.fr/hal-02129569}

Submitted on 15 May 2019

HAL is a multi-disciplinary open access archive for the deposit and dissemination of scientific research documents, whether they are published or not. The documents may come from teaching and research institutions in France or abroad, or from public or private research centers.
L'archive ouverte pluridisciplinaire HAL, est destinée au dépôt et à la diffusion de documents scientifiques de niveau recherche, publiés ou non, émanant des établissements d'enseignement et de recherche français ou étrangers, des laboratoires publics ou privés. 


\title{
Autostereoscopic transparent display using a wedge light guide and a holographic optical element
}

\author{
Thomas Crespel ${ }^{1,2,3}$, Patrick Reuter ${ }^{1,3,4}$, Xavier Granier ${ }^{2,5}$, Adrian Travis ${ }^{6}$ \\ ${ }^{1}$ Inria Bordeaux Sud-Ouest 200 Avenue de la Vieille Tour, 33405 Talence, France \\ ${ }^{2}$ LP2N / Institut d'Optique d'Aquitaine, Rue Francois Mitterrand, 33400 Talence, France \\ ${ }^{3}$ Université de Bordeaux, 351 cours de la Libration, 33405 Talence, France \\ ${ }^{4}$ LaBRI, 351 cours de la Libération, 33405 Talence, France \\ ${ }^{5}$ Archéovision, Archéopôle d'Aquitaine, Esplanade des Antilles, 33607 Pessac, France \\ ${ }^{6}$ Travoptics, 62 avenue de Flandre, 75019 Paris, France
}

\begin{abstract}
We present a novel transparent autostereoscopic display consisting of laser picoprojectors, a wedge light guide and a holographic optical element. Such a display can superimpose 3D data on the real world without any wearables. (C) 2019 The Author(s)

OCIS codes: $120.2040,090.2870,100.6890$,
\end{abstract}

\section{Motivation}

Augmented Reality (AR) dedicated systems such as Hololens and Meta provide stereoscopic augmentation using transparent displays but require to wear a headset. We propose a transparent display similar to a head-up display that provides autostereoscopic capabilities: separate views are addressed to each eye independently and without wearing any glasses or headset. The user can also move the head horizontally and perceive motion parallax without tracking. Our work is inspired from a non-transparent multi-projection display using conventional optics in combination with a wedge light guide [1]. On the contrary, our work results in a transparent display.

\section{Method}

The principle of our display is to couple beams from multiple "laser beam-steering" picoprojectors into a transparent light guide and then to redirect each beam to separate viewing zones (VZ) using a transparent Holographic Optical Element (HOE).

The light guide we use is a wedge-shaped light guide [2]: rays are guided with total internal reflection in a slab (referred to as the "expansion part" in Figure 2). At the "wedge part", one face of the guide is tilted relatively to the other so that the rays' angles with respect to the normal decrease at each bounce, until they reach the critical angle and escape the guide. This shape is extruded so that the projected image can expand in one dimension while being guided in the other. Rays leave the guide collimated with an angle nearly parallel to the guide direction, while they still fan out on the other direction (perpendicularly to the figure).

A transmission HOE is clamped to the wedge exit surface in order to redirect light rays from projectors to pre-defined VZs as shown in Figure 2(a). Figure 2 also shows that we only use a small portion of the wedge area that corresponds to the lateral expansion of the projected images. The HOE achieves multiple optical functions: a Fresnel mirror that straightens each ray leaving the guide at grazing angle to a normal direction, a cylindrical lens that turns the diverging beam into a converging beam, and an anisotropic diffuser that makes each point of the VZs lit by every point of the hologram.

We have recorded the transfer function of the central position of the projector: the signal beam reproduces the conjugated beam of the output of the wedge guide, incident at grazing angle on the hologram, while the object beam is created by lighting a $3 \times 10 \mathrm{~cm}$ diffuser (size of the VZ) located at $50 \mathrm{~cm}$ (observation distance) from the hologram. The lateral size of $3 \mathrm{~cm}$ of each VZ is chosen according to the mean interpupillary distance.

The beams from adjacent projectors are reconstructed within the angular Bragg limit of the HOE: an angle shift of $\Delta \theta$ in the input from the angle of recording results in the same shift on the output while $\Delta \theta<\Delta \theta_{\text {Bragg. }}$. In this



Fig. 1. Principle of a wedge guide 


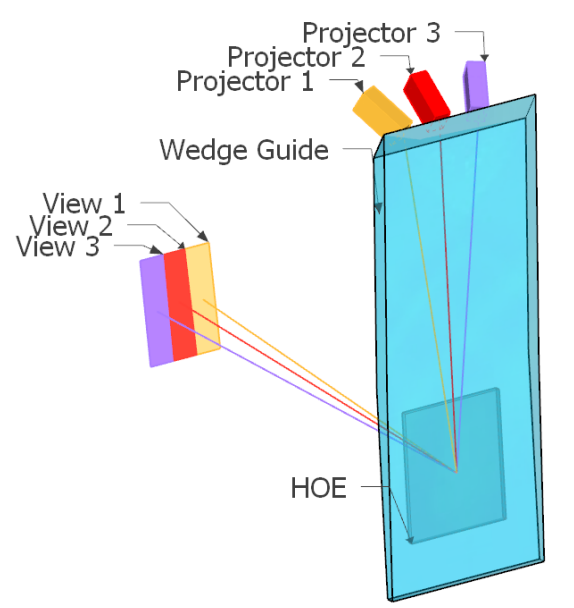

(a)





(b)
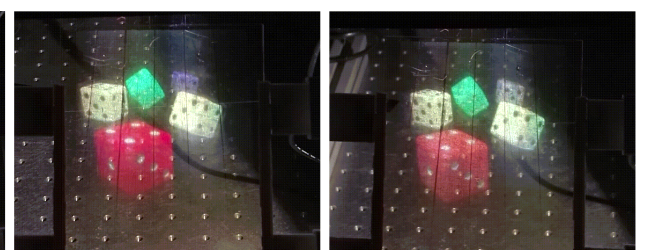

(c)

Fig. 2. (a) Drawing of light paths from three projectors to the corresponding VZs (b) Picture of the current prototype demonstrating the hologram function (c) Pictures taken from three different VZs

way, the VZs can be displayed side by side along the field of view if the projectors are properly positioned at the entrance of the wedge guide. In normal conditions of observation and lighting $\left(\Delta \theta \gg \Delta \theta_{\text {Bragg }}\right.$ ), only the light from the projectors is diffracted, and the HOE is perceived as transparent. We have measured $\Delta \theta_{\text {Bragg }} \approx \pm 10^{\circ}$ for our HOE, imposing a maximum number of 9 projectors in our current setup.

We have recorded a monochromatic green HOE and a RGB multiplexed HOE. The monochromatic one behaves as expected, whereas the full-color one presents some chromatic aberrations that are due to a too large wavelength selectivity of each grating.

In order to create and display content on our device, we use a custom software written in C++/OpenGL that renders multiview images after a calibration step. The calibration consists in correcting the guide distortion and aligning images from different projectors.

\section{Conclusion}

We have demonstrated the feasibility of a compact, autostereoscopic transparent display with multiple projectors and a custom HOE. Our current prototype has three views but we think it is theoretically able to generate up to 9 views, providing binocular vision and horizontal motion parallax. Vertical parallax could be implemented with head tracking, for example. The views are located $50 \mathrm{~cm}$ in front of the display, they are $3 \mathrm{~cm}$ wide and $10 \mathrm{~cm}$ high. These values are fixed once the HOE is recorded; they result from our choices and can be changed in the recording step. This display has great potential for AR applications such as augmented exhibitions in museums or shops, head-up displays for vehicles or aeronautics, and industrial maintenance, among others.

\section{Acknowledgments}

We thank Yves Gentet and Pierre Picard from Ultimate Holography for their great help in designing the HOE. We also thank the Région Nouvelle Aquitaine for funding such a project.

\section{References}

1. Chang-Kun Lee, Soon gi Park, Seokil Moon, Jong-Young Hong, and Byoungho Lee. Compact multiprojection 3d display system with light-guide projection. Opt. Express, 23(22):28945-28959, Nov 2015.

2. ARL Travis, F Payne, F Zhong, and JR Moore. Flat panel display using projection within a wedge-shaped waveguide. In Proceedings of the 20th International Display Research Conference, volume 2000, pages 292-295. Society for Information Display (SID), 2000. 